\title{
EL SEÑORIO DE LA VALL DE PERPUTXENT (SIGLOS XIII-XIV)
}

\author{
Enric Guinot Rodríguez \\ Universidad de Valencia
}

La Vall de Perputxent es un valle formado por el río Serpis entre las sierras de Benicadell y Albureca, orientado de SO a NE, justo en el límite entre las provincias de Alacant y València. Actualmente comprenderia los términos municipales de Beniarrés y L'Orxa, pero en los siglos medievales poseía una unidad organizativa mucho más nítida.

El tipo de organización territorial en la Valencia musulmana estaba basado en los castillos y sus áreas respectivas de influencia, delimitadas frecuentemente por las características geográficas. Esta concepción de valle estaba muy generalizada por todo el país, constando de un castillo situado en un punto alto sobre la zona circundante, con un carácter básicamente defensivo para la población cercana, y diversas alquerias como núcleos de población dispersos relacionados con dicho castillo '.

Perputxent no es una excepción y en ella encontramos el castillo roquero de dicho nombre, situado a escasa distancia de la actual población de L'Orxa, y varias alquerías en su entorno: la citada L'Orxa, Alquinencia, Benillup y Benitaric, a las que se añade la de Beniarrés, que correspondia a un núcleo cercano al término del castillo musulmán de Perputxent pero fuera de él, en época musulmana, pues es adquirido por Ramón de Riusec en 1273 de forma separada a la de la Vall, y la documentación del siglo XIII siempre diferencia claramente ambos grupos territoriales. Mientras las primeras alquerias citadas son de la Vall de Perputxent, de Beniarrés se dice que está en los términos de dicho castillo, proceso que tenderá a su identificación bajo el topónimo Vall de Perputxent sólo con el tiempo y a medida que bajo dominio cristiano mantuvieron su unidad organizativa en un mismo señorío. 
Igualmente no está clara la existencia de un núcleo de población en el mismo castillo pues la documentación de los siglos XIII y XIV siempre se refiere a alguna de las alquerias del término, principalmente L'Orxa y Beniarrés, o al castillo como tal, pero no a una población llamada Perputxent ${ }^{2}$.

La conquista cristiana de la zona está relativamente confusa todavía debido a las lagunas en la documentación, pero también influye el propio proceso bélico y las características con que se desarrolló dicha conquista en los territorios al sur del Xúquer. Si un factor fue la confusión en los límites de las zonas de conquista entre Castilla y la Corona de Aragón, a ello se unió la existencia de pactos entre Jaume I y diversos poderes locales más o menos independientes, caso del propio rey de Valencia Abu Zayd ${ }^{3}$, en lo que sin duda respondía a una problemática real: la falta de recursos humanos por parte cristiana para efectuar una ocupación militar real al sur del Xúquer.

Precisamente el único pacto de dicho tipo que se ha conservado es el efectuado con al-Azrâq, jefe musulmán de origen incierto pero que ejercia un poder real en la zona situada más o menos entre Denia y Cocentaina, en cuyos términos se incluye la Vall de Perputxent.

Este pacto se realizó a mediados de abril de 1244, probablemente con una nueva versión al año siguiente, siendo el primero un tratado de paz, mientras en el segundo al-Azráq reconocía la soberanía de Jaume I y le entregaba los castillos de Pop y Tarbena, en señal de ello, reteniendo él durante tres años más otros seis castillos de la zona, entre ellos el de Perputxent, las rentas de los cuales compartirian en ese período ambos; al finalizar éste al-Azrâq conservaría en plena propiedad precisamente los castillos de Perputxent y Alcalà ${ }^{4}$.

Con todo, lo que retenemos es la permanencia de la Vall de Perputxent en manos de sus mismos pobladores musulmanes e incluso de su "señor» musulmán - sea cual sea el sentido de dicha palabra en ese período-. una vez producida lo que se Ilamaría conquista cristiana de la zona.

Permanencia que se prolongó en el tiempo dado que antes de finalizar el pacto citado anteriormente se produjo en 1248 la primera revuelta general de los musulmanes contra el dominio cristiano, quedando Perputxent claramente dentro de la zona rebelde controlada por al-Azrâq, y por lo que parece ello se prolongó hasta el último momento de su rendición a Jaume ! en 1258.

Precisamente en el año de 1248 Jaume I habia hecho las primeras donaciones que constan en el Repartiment, de tierras de Perputxent a cristianos; en concreto 57 jovadas a Martí de Picasent y otros 19 pobladores en el término del castillo, sin concretar lugar 5 , pero dadas las circunstancias del momento y la duración de la revuelta musulmana no parece muy claro que tuviesen efectiva vigencia, al menos hasta la rendición de 1258 , siendo probable que a partir de entonces fuese efectiva 
alguna de dichas donaciones, al menos hasta el paso del castillo en 1260 a manos señoriales; incluso sería posible que dada la fecha de la donación, 12 de mayo de 1248, ya iniciada la revuelta musulmana, hubiese el deseo real de establecer una comunidad cristiana en un lugar significativo desde el punto de vista militar y con fines defensivos en la zona, perdurando alguno de estos asentamientos en las dos décadas siguientes, y de ahí las citas de propietarios cristianos en esas fechas aunque, como se verá, irán desapareciendo.

Pero si tras la rendición de al-Azrâq algunos castillos de la zona todavía permanecieron en manos de diversos personajes musulmanes durante varios años ${ }^{6}$, no parece que fuese el caso de Perputxent, el cual ya no es citado en dicha situación y tan sólo dos años después, el 18 de marzo de 1260 fue dado por Jaume l a Gil Garcés de Azagra, a cambio de la población de Planes, que tenía anteriormente ${ }^{7}$.

Esta primera donación de Jaume I es muy breve en su contenido, limitándose a destacar el carácter de «hereditatem propiam francham et liberam» con que hace la concesión, y hablando en concreto de "castrum et villam", aunque en este caso quizás fuese o una fórmula legal o una realidad de poblado cristiano ocupado por algunos titulares de esas primeras donaciones de 1248 y que no tuvieron mucha continuidad en el tiempo como tal núcleo de poblamiento ${ }^{*}$.

Como en tantas donaciones de ésta época, estamos en el momento en que este castillo pasó del realengo al señorio, del que ya no salió en ningún momento; sin embargo la donación no especificaba para nada cuáles eran las condiciones de dicho señorio con respecto a la renta feudal; ni tan siquiera en este caso parece que el monarca se retuviese algún derecho concreto.

En la década siguiente no hay noticias documentales sobre la situación en el señorio, excepto que el citado don Gil Garcés de Azagra fijó unas costumbres para la población musulmana y efectuó una división de heredades, aunque sin referencias claras a la existencia de población cristiana".

Al morir el citado Gil Garcés hacia finales de 1271, dejó encargado en su testamento que se vendiesen sus bienes en el reino de València, para con el dinero que se sacase saldar sus deudas; y así, los albaceas del testamento, sacaron en subasta pública el castillo y villa de Perputxent el día 12 de junio de 1273, en la localidad de Ontinyent, tras treinta dias de oferta pública, siendo vendido al mejor postor, Ramón de Riusec, ciudadano de València, quien pagó 70.000 sueldos por él ${ }^{10}$.

En el documento de venta se constáta un salto cualitativo muy importante con respecto a la cesión original del castillo pues ahora se detallan muy minuciosamente todos los derechos que comportaba la posesión del señorío, desde las partes del castillo hasta los hombres que viven en el término, pasando por todos los monopolios clásicos: hornos, molinos, 
baños,etc., y sobre todo indicando la posesión señorial del monedaje o morabati, del derecho militar -host e cavalcada-, y de toda la justicia, civil y criminal.

Quedan muy claras pues cuáles son las condiciones-marco del señorío de Perputxent, en concreto con el reparto de funciones con la monarquía, la cual en estos momentos no se retiene ningún derecho en el término. Por contra el documento no indica nada sobre cuáles son las condiciones concretas en que están establecidas las relaciones señorcampesinos, e incluso tampoco se llega a concretar qué núcleos de población son los comprendidos; sólo se habla del «castrum et villam» de Perputxent, y de sus alquerias.

La confirmación de dicha venta hecha por el propio rey el 12 de junio de 1273 nos permite saber que la situación del anterior señor de Perputxent era muy delicada pues el castillo no lo tenia él sino un tal Sanç Pere d'Elenda como garantía para cobrarse una deuda de 67.000 sueldos, lo que explicaría las razones de la venta y sus peculiaridades, pues Ramon de Riusec, tal como atestigua el rey, entregó 67.000 de los 70.000 s. del precio de venta al citado acreedor, entrando así ya en posesión del castillo y su término "'. Igualmente el texto ahora sí parece indicar la existencia de pobladores cristianos y musulmanes en el lugar, aunque la forma de redacción no permita ser categóricos.

Antes de pasado un mes de dicha confirmación, Jaume I mandó a Joan de Monçó que hiciese entrega de Perputxent al citado Ramon de Riusec; antes de hacerlo, aquel, como alcaide del castillo de Benicadell, fijó los límites del término tocante a la alquería de Rugat, en la zona montañosa, en concreto por la partida o alquería quizá de Almartinyen, del que se dice era disputado entre ambas poblaciones; para solucionarlo fueron citados varios personajes musulmanes del contorno y tras consultar con ellos, se fijó la división de aguas como límite de ambos términos ${ }^{12}$.

Casi a continuación, el 2 de septiembre de 1273, Ramon de Riusec compraba a doña Teresa Gil de Vidaure y a sus hijos Jaume y Pere, conjuntamente, la alquería de Beniarrés, vecina al término de Perputxent pero claramente fuera de él, tal como señala varias veces el documento de venta ${ }^{13}$. En él se indica que pertenecía al castillo de Travadell, de cuyo término la separan, anulando cualquier tipo de dependencia, incluso militar o eclesiastica, y uniéndola al término de Perputxent. La venta, valorada en 7.000 sueldos, incluía todos los derechos señoriales en el lugar, monopolios, servicios militares y justicia civil y criminal, junto lógicamente con todas las tierras y sus ocupantes, de los que no indica religión aunque indudablemente existe una población.

Con esta adquisición quedó ya constituido territorialmente el señorio de la Vall de Perputxent en la forma en que perduró en los siglos posteriores, e igualmente la existencia de núcleos de población en él hace pensar que dispondrían de unas costumbres o carta puebla que regularían el nivel de la renta feudal exigida por el señor. 
Lo cierto es que no se conserva ninguna prueba documental y hay que esperar dos años más a que el citado Ramón de Riusec dé una carta puebla a su señorio, aunque sólo lo haga para la alquería de Beniarrés. El 25 de abril de 1275, en su casa de València, se redacta y firma dicha carta puebla, lo que implicaba que la población existente anteriormente, sin duda musulmana, se ha ido o ha sido expulsada, no lo sabemos exactamente, y ahora el señor del lugar aprovecha para instalar un núcleo exclusivamente cristiano, diez pobladores, y, como en tantos otros lugares, no en la misma fortaleza sino en un lugar o alquería del término ${ }^{14}$.

El texto indica claramente que existian unos campos y unas casas y que se los podian repartir como les pareciese mejor a ellos, debiendo quedarse cada uno una casa y una hanegada de regadío para huerto, cosas ambas que se las reconoce francas de todo derecho enfitéutico, y reservándose el señor sólo la torre de la alquería, las casas que rodeaban dicha torre, el almudín y una jovada de tierra de secano como reserva señorial dedicada a la viña.

Los citados campesinos debian hacer residencia personal en el lugar y a cambio del establecimiento enfitéutico de las tierras debian entregar al señor lo que el documento llama tascha, censo por las tierras que documentos posteriores ${ }^{1.5}$ nos indican que debía ser una participación de 1/11, ya fuese secano o regadio, pero que la puebla en cuestión no detalla pues se limita a señalar que se debe dar como en el resto del reino y afectando a todos los frutos, granos en la era, vino de la vendimia, olivas, higos y almendras.

Igualmente les exigia hacer servicio militar en defensa del castillo de Perputxent y seguir a su señor cuando éste fuese requerido por el rey en defensa del reino, mientras que el diezmo y la primicia lo pagaban íntegramente a la iglesia - caso excepcional entre los señorios que se incorporarán a Montesa posteriormente-.

Por último la carta puebla detalla la cesión libre a los pobladores de todos los recursos naturales del término, leñas, pastos, aguas, caza, etc., y curiosamente omite toda referencia a la situación de los monopolios clásicos: horno y molinos especialmente. Pensamos que ello no quiere decir que no estuviesen en manos señoriales pues los documentos de venta del señorío los incluian y un pueblo sólo tiene franquicia de un monopolio cuando tiene el documento que lo demuestra, y ese no es el caso de Perputxent ni ahora ni más adelante, por lo que parece lógico pensar que en esa etapa simplemente no habria molino u horno en dicha localidad ${ }^{12}$.

La situación es, pues, de varias alquerias no concretadas todavía documentalmente, con población musulmana, y casi seguro regulada la renta feudal en ellas por algún o algunos documentos, y la inclusión de un núcleo cristiano con unas condiciones de renta feudal que en principio no se pueden considerar gravosas aunque precisamente al ser condiciones iniciales no queden delimitados ciertos aspectos. 
Sin embargo y antes de que terminase el año de 1275 se inició la segunda revuelta general de los musulmanes valencianos que se iba a extender durante todo el año siguiente ${ }^{17}$, afectando claramente a todas las comarcas vecinas a la Vall de Perputxent aunque no hemos encontrado ninguna noticia que hable sobre qué pasó exactamente en este señorío. Quizá esa carencia responda a una situación en la que a pesar de las tensiones no se concretó en la Vall ningún hecho destacado que alterase el "statu quo».

En cambio sí se produjo una alteración significativa en la posesión del señorio, pues un par de meses después del inicio de la revuelta musulmana, el 16 de enero de 1276, el señor de Perputxent, Ramón de Riusec, cambiaba dicho lugar por el señorio de Ribarrotja al caballero Arnau de Romaní ${ }^{18}$, sin que consten en el documento las razones de dicho concambio y si tenían relación o no con la situación musulmana.

Respecto a su contenido no aporta datos nuevos, limitándose a enumerar los recursos naturales y derechos tradicionales señoriales que tenía en cada población y quizá lo más destacado sea, junto a la constatación de cuál es la jurisdicción señorial en estos pueblos, limitándose a citarla como «iurisdiccionibus» en vez de utilizar la forma común de «merum et mixtum imperium», o indicar que es sólo una de las dos.

Durante el reinado de Pere III el señorío se mantuvo en las manos de mossen Arnau de Romani, y por lo que parece hubo ciertos altibajos en la presencia de población cristiana en él. Según el inventario de carácter eclesiástico «rationes decimarum», de 1278-79, en el que se detallan las parroquias del reino y cuál sería el valor económico de sus bienes y rentas, la parroquia de Perputxent sería de las pocas que existían real y materialmente en la comarca ${ }^{19}$, núcleo que sin duda hay que identificar con Beniarrés.

Pierre Guichard por su parte aporta algunos documentos que hablan de la presencia de cristianos también en la alquería de Benillup ${ }^{20}$. Se pregunta si no tendrán su origen en aquellas donaciones que se produjeron en 1248 y que consideramos en su momento como bastante comprometidas dada la revuelta musulmana coetánea aunque era probable que hubiesen sido ocupadas realmente una vez sofocada aquella.

Lo cierto es que en la primera mitad de la década de los 80 se documentan varios casos de pobladores cristianos y también su muy probable extinción en Benillup: «El primer texto, de 1281, es el establecimiento de una heredad en Benillup «semejante a las de los otros pobladores del lugar», hecho por Arnaldo de Romaní a un tal Guillermo Sutor. Se indica que la heredad ha sido confiscada a otro poblador en razón de su ausencia. Pero más tarde, en 1284-86, hallamos varios contratos en los que Arnaldo de Romaní vuelve a comprar a bajo precio las heredades de los pobladores de Benillup. Todas las tierras de los cristianos de Benillup debieron de ser compradas de esta forma y arrendadas a nuevos pobladores musulmanes...»21. 
Posteriormente y ya en 1285, el señor de Perputxent, mossen Arnau de Romaní, decidió dar una carta puebla para la comunidad musulmana que en cierta manera ratificaba la primera dada por Gil Garcés de Azagra. En ella lo más destacado era la obligación de pagar un almagram y una alfarda, sin que se concretase en que niveles quedaban fijados, probablemente porque eran los corrientes y conocidos en la zona, así como el efectuar 6 dias de trabajo al año por cada heredad, aspecto éste equiparable o entendido como la cofra de época musulmana trasladada al mundo feudal cristiano como prestación personal; además también pagaban diezmo y primicia de todos los frutos, se fijaba una dehesa y se reconocian aparte las propiedades de los cristianos ${ }^{22}$.

El cambio más destacado en el señorio se produjo 4 años después, el 24 de enero de 1289, cuando su señor, Arnau de Romaní, quizá hijo del anterior Arnau de Romaní, pues se titula así el mismo en el documento, hace promesa a fr. Bernat de Miravalis, vicegerente de comendador de la casa de la Orden del Hospital de San Juan de Jerusalén en València, de que entrará como fraile de la Orden en un plazo comprendido entre ese día y Navidad. En el mismo documento hace, no donación, sino venta real de su señorío de Vall de Perputxent a la citada Orden, por un precio de 30.000 sueldos, 20.000s. pagaderos en ese momento y el resto a repartir en los dos años siguientes ${ }^{23}$.

En este documento de cesión una vez más se repiten los elementos tipicos constituyentes del señorío, con menciones concretas a molinos y censos enfitéuticos y, ahora sí, a la justicia civil y criminal en manos señoriales, aunque por contra no se cite ni el monedaje ni los servicios de "host e cavalgada».

La documentación en este momento sufre un vacio con respecto a Perputxent y hay que esperar nada menos que a 1316 para que veamos actuar de nuevo a la Orden del Hospital en este lugar. Es lógico pensar que en el período intermedio habría desde una ratificación de las pueblas y franquicias de las dos comunidades, como siempre se hace al cambiar de manos un señorio, a diversos establecimientos y actuaciones concretas, pero no se puede documentar nada de ello.

Con todo no deja de llamar la atención el hecho de que no sea hasta 27 años después de la entrada de Perputxent cuando la Orden del Hospital decida alterar la carta puebla anterior de la población musulmana para darles una nueva, que además aparece titulada en la documentación como "carta de la primera població de la vall de Perputxen».

Lo cierto es que el 13 de junio de $1316^{24}$ el castellán de Amposta de la Orden del Hospital, fr. Martí Perez d'Oros, por lo que indica el documento totalmente a iniciativa de la Orden, hace un nuevo establecimiento de las casas y rahales a sus pobladores musulmanes, de los que da el nombre uno por uno ${ }^{25}$, confirmándolos en ellas según han sido establecidos por el alamín de la aljama. 
Da la impresión que hay un intento por parte señorial de unificar situaciones, pues las pueblas anteriores hablaban sólo de L'Orxa y Alquinencia, y ello podría implicar que no todos los musulmanes pagasen igual por sus tierras, à lo que se añade claramente el que con la nueva puebla se rompe ya totalmente con la terminología anterior de derechos y características musulmanas -almagram, alfarda, etc.-- para ser introducidos a nivel general los censos típicos cristianos.

En cuanto a su contenido se constatan inmediatamente dos aspectos; uno, el mayor nivel de exigencia señorial y el aumento claro en la renta feudal obtenida de la población musulmana, y por otro la clara diferencia en el nivel de la renta feudal entre campesinos cristianos y musulmanes, mucho más dura para los segundos.

Los censos exigidos a los campesinos musulmanes a partir de ahora abarcan toda la gama de posibilidades: prestaciones personales, de 4 días de trabajo al año para el señor —o dos sueldos-, englobados bajo el termino çofra; censos fijos en metálico: tres sueldos y medio como besante; y censos fijos en especie: un par de gallinas, dos almudes de trigo y dos de panizo al año, por el mes de enero, y por rahal, diríamos por unidad familiar de explotación.

Sobre la ganadería, lógicamente la Orden tiene interés en gravar los animales que existan y así sólo fija censo sobre colmenas y cabras, dos dineros y medio al año por cada una de las primeras y un dinero y medio por cada animal de las segundas.

La parte más significativa de la renta feudal sobre los campesinos musulmanes sin embargo la formaba la participación de frutos que les era exigida ahora, fijándose cantidades proporcionales a cada tipo de cultivo: la viña varía de $1 / 3$ de participación de cosecha en el regadío a 1/8 en el secano; las higueras hacian un tercio también en el regadio pero ya $1 / 5$ en el secano, mientras el olivar llega nada menos que a $1 / 3$ de participación en todos los casos.

Por último, en los cereales, del tipo que fuesen, "frumenti, panici, adacie quam ordi», la proporción era medio almud por cahiz, esto es, 1/8 de participación.

Todavia la Orden del Hospital se retuvo la facultad de elegir "alcadi» cuando le pareciese y cobró 10 sueldos a cada uno de los musulmanes a los que establecía estos rahales en concepto de «entrada».

En resumen y recordando los conceptos apuntados en la carta puebla a los cristianos de Beniarrés se comprueba una fuerte disonancia entre ambos niveles de la renta feudal, con una situación mucho más favorable y menos exigente para los cristianos, quienes no sólo contaban con una participación muy inferior en algunos casos sino que tenían asegurado el uso franco de ciertas tierras y recursos.

Probablemente también se podria pensar en un intento de los Hospitalarios por aumentar la presión y exacción sobre el campesino musul- 
mán pues estas nuevas condiciones son bastante más amplias en sus exigencias que las de la puebla anterior, constatándose que ya ha desaparecido todo vestigio de comunidad musulmana como tal; ahora se les trata igual que a una comunidad cristiana con respecto a los mecanismos de apropiación de parte del excedente, pues incluso aunque no se hable de los monopolios es evidente su control señorial a todos los niveles.

Cuando la Orden del Hospital dio esta carta puebla a los musulmanes de Perputxent ya se había puesto en marcha el mecanismo que iba a llevar a dicho señorio a manos de la Orden de Montesa. Iniciado el proceso con la disolución de la Orden del Temple a nivel internacional y continuado con la resistencia de Jaume II a aceptar la integración de todos los bienes de ella a los de los Hospitalarios, se llegó a una solución con el acuerdo monarca-Papa Juan XXII para crear una nueva Orden en la Corona de Aragón, la de Santa María de Montesa ${ }^{26}$.

Uno de los capítulos de dicho acuerdo era la integración de los señoríos Hospitalarios en el reino de València a la nueva Orden de Montesa, cosa que se produjo efectivamente sólo el 17 de julio de 1319 , fecha de fundación de Montesa en Barcelona.

En el periodo intermedio, en 1317 y 1319, Perputxent al igual que los otros lugares valencianos afectados por el acuerdo permanecieron bajo administración real, tal como había sucedido con los lugares de los Templarios desde 1312, y ello sin duda llevó a que ciertas poblaciones, como Ares, Les Coves, Culla y la propia Vall de Perputxent intentasen resistirse a su paso de la administración real a un nuevo señorio, pero Jaume ll se mantuvo inflexible en sus designios sobre la Orden de Montesa y el 1 de marzo de 1320 daba poderes a su consejero Vidal de Vilanova para absolver a los lugares citados del juramento de homenaje y fidelidad que le habian hecho en su momento, argumento que era utilizado para no prestar nuevo homenaje de fidelidad a Montesa ${ }^{27}$.

El Maestre de la Orden, fr. Arnau de Soler, tomó posesión del lugar al poco tiempo y el 5 de abril de ese año procedia a liquidar el salario que le correspondía por seis meses y medio a Pere Colom, ciudadano de València, en razón de haber tenido la custodia del castillo en el interregno entre el rey y la Orden ${ }^{2 x}$.

El mismo día el citado Maestre de Montesa procedió a ratificar y confirmar en todos sus puntos la carta puebla que tenían los cristianos residentes en la alquería de Beniarrés ${ }^{29}$, con lo cual la nueva Orden aceptaba totalmente la situación señorial que recibía,-sin intentar introducir cambios en esta primera época.

Sí llama la atención un problema que se plantea al constatarse que según el inventario que la misma Orden realizó en ese año de 1320 de todos los derechos señoriales que tenía en cada uno de los pueblos ${ }^{30}$, Montesa sólo disfrutaba en el lugar de la mitad del monedaje y la jurisdicción civil. Hasta este momento le hemos ido siguiendo el hilo documental 
a ambos aspectos y siempre se hablaba en las ventas o traspasos del señorío de que el titular tenía todo el monedaje y toda la jurisdicción, civil y criminal, por lo que no queda muy claro cuál ha sido el proceso en el último período, si ha habido alguna retención real durante el señorio Hospitalario o si es consecuencia de la forma en que accedió este lugar a manos de Montesa; sí queda muy claro que la situación efectiva desde ese instante es la que indica el citado inventario, tal como hemos podido comprobar en diversos documentos de la propia Orden ${ }^{31}$.

A partir de ahora y poco a poco Montesa irá organizando el señorío que llegaba a sus manos y tomando diversas disposiciones, aunque ello no representó en ningún momento un corte a una alteración en el nivel establecido de las relaciones de producción.

La situación en el valle era de coexistencia de cuatro núcleos o alquerías pobladas por musulmanes: L'Orxa, Benillup, Alquinencia y Benitàric, con un total de 60 casas, y un núcleo de cristianos, Beniarrés, con 30 casas, junto al castillo lógicamente ocupado también por cristianos. Pero con el tiempo si quizá se había mantenido la homogeneidad de hábitat no debió pasar lo mismo con la explotación de la tierra y vemos cómo hay algún cristiano con propiedades enfitéuticas en L'Orxa y algún musulmán con rahales y casas en Beniarrés ${ }^{32}$.

La Orden de Montesa por su parte se dedicó a ratificar algunas ventas que se hicieron en estos primeros momentos, en concreto las de unos cristianos que venden todas sus parcelas situadas en L'Orxa a varios musulmanes residentes alli, y a intervenir en algún caso especial como puede ser la legalización de la posesión de un rahal por un matrimonio cristiano pues en su momento esas tierras fueron confiscadas a un musulmán rebelde, o incluso procede a establecer nuevas tierras en enfiteusis a vecinos del lugar ${ }^{33}$.

También en las mismas fechas, 8 de abril de 1320, fr. Arnau de Soler arrendó el molino de la Portella, en el término del castillo, a un vecino de Perputxent, por 6 años y 400 sueldos/año ${ }^{34}$; a los pocos dias procedió a arrendar por un año todas las rentas señoriales del lugar, a un Pere Colom que probablemente sea el mismo que tuvo el castillo en custodia hasta su posesión por la Orden unos meses antes ${ }^{35}$.

A nivel organizativo el Maestre de Montesa nombró también en este primer año a fr. Ferran Peres d'Aragó como comendador de Perputxent, lo que implicaba la constitución de tal lugar como encomienda, dándole poderes de justicia sobre los vecinos y derecho a recibir el valor de las multas ${ }^{36}$, siendo completado dicho cargo días después con el nombramiento de fr. Berenguer de Montoliu como lugarteniente y procurador del Maestre en Sueca, Silla, Montesa, Perputxent y València, con funciones de gestión económica y de derechos señoriales, arrendamientos y establecimientos enfitéuticos ${ }^{37}$. 
Por último y ya algunos años después, concretamente el 14 de noviembre de 1334, en Sueca, el maestre fr. Pere de Tous, a petición de los musulmanes de L'Orxa redactaba lo que la documentación llama «carta de la segona població del vall de Perpunxen", y que en realidad es un añadido a la carta puebla de los musulmanes con rerspecto a temas que no se trataron en su momento ${ }^{38}$.

Concretamente los temas tratados son la regulación del monopolio de hornos, resuelto con el sistema de que cada vecino cueza su pan en su casa o como quiera y sea pagado a la Orden elfornatge, esto es, 8 dineros al año, por San Martín, por cada musulmán mayor de 3 años.

Igualmente se regula el equivalente al monopolio de herrería, esto es, los moros podrán fabricar o construir sus arados y herramientas donde quieran y como quieran, pagando la aljama en su conjunto 10 sueldos al año también en San Martín.

Sí es seguro que fue a petición de los vecinos la regulación que se hace de la forma de prestación del trabajo personal y del suministro de viveres y alimentos al Comendador o Maestre pues eran precisamente los puntos de mayor facilidad para abusos señoriales. Acuerdan que deberán trabajar en obras de reparación o mejora cuando el Maestre o el Comendador lo deseen, recibiendo un salario bajísimo, de 6 dineros al día por hombre o por asno, y de 12 dineros por mulo. En cuanto a los víveres, se acuerda que el Maestre o el comendador puedan coger pollos o los animales que más les gusten, pagando 12 dineros por par de gallinas o por cabra, y 6 dineros por par de pollos.

Por último se regulaba el salario máximo que debian pagar al guardián de los campos del término, estableciendo que fuese una barcella de grano mezclado y una garba de lino por heredad.

Como vemos pues, cada vez la comunidad musulmana va integrándose más y más en las formas y mecanismos de exacción señorial típicos y generales en el feudalismo valenciano y sin duda van siendo sometidos a mayores presiones que sus convecinos cristianos; además da la impresión de que logran capear las nuevas exigencias con bastantes más problemas que éstos. En cierta manera parece que como mucho intenten solamente salvar lo salvable, probablemente porque no podrían hacer mucho más. A partir de ahora Perputxent se mantendrá dentro del señorio de Montesa, como una encomienda independiente pero de escasa importancia económica a lo que se añadirá la lejanía con respecto al núcleo central del señorío e incluso de la capital del Reino, jugando un papel siempre bastante marginal dentro de la Orden y no siendo un destino codiciado ni mucho menos entre sus freiles. 


\section{NOTAS}

(1) P. GUICHARD, Nuestra Historia, Valencia, 1980, vol. 2. También del mismo autor, "Los castillos musulmanes del norte de la provincia de Alicante», en Anales de la Universidad de Alicante. Historia Medieval, t. 1, 1982, pp. 29-46; y «El castillo y el valle del Pop durante la Edad Media: Contribución al estudio de los señoríos valencianos", en Anales de la Universidad de Alicante. Historia Medieval, N. ${ }^{\circ} 2,1983$, pp. 19-32.

(2) Sobre el castillo musulmán de Perputxent y sus características, con un estudio arqueológico: A. Bazzana, P. Guichard y J. M. Segura Marti, "Du hisn musulmán au castrum chretien: le chateau de Perpunchent (Lorcha, province d'Alicante)», en Mélanges de la Casa de Velázquez, t. XVIII, 1982, pp. 449-465.

(3) P. GUICHARD, Nuestra Historia, vol. 3, p. 27.

(4) Fco. de P. MOMBLANCH Y GONZALEZ, Al-Azraq, capitán de moros, Valencia, 1977; P. GUICHARD, Nuestra Historia, vol. 3, p. 27. Véanse las matizaciones y sugerencias muy interesantes que sobre la figura de al-Azrâq y su situación social dentro del contexto de la feudalización hace M. C. BARCELO TORRES, "Documentos árabes de al-Azraq (12451250)", Saitabi, t. 32 (1982), pp. 27-42.

(5) A. CABANES-R. FERRER, Llibre del Repartiment, Zaragoza, 1979, vol. 2, p. 175. Un estudio de estos establecimientos junto a los demás de la zona de Alacant, en R. FERRER NAVARRO, «La repoblación de una comarca alicantina: la Serranía de Alcoy", en Anales de la Univ. de Alicante. Historia Medieval, N. ${ }^{\circ}$, pp. 9-28, e íd., "Repoblación de tierras alican-

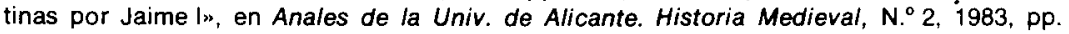
33-48; sin embargo, P. Guichard sitúa la donación citada en la alquería de Benillup y le atribuye 81 jovadas, en Nuestra Historia, vol. 3, p. 59.

(6) P. GUICHARD, Nuestra Historia, vol. 3, pp. 32-33.

(7) Archivo del Reino de Valencia (A.R.V.), Real Cancillería, N. ${ }^{\circ} 614$, fol. 22 . Archivo Histórico Nacional de Madrid (A.H.N.), Ordenes Militares (OO.MM.), Montesa, Libro 543c; publicado por A. HUICl-A. CABANES, Documentos de Jaime / de Aragón, Zaragoza, 1982, vol. IV, p. 255.

(8) Sobre este tema, véase el muy interesante artículo de P. GUICHARD, "Los castillos musulmanes del norte de...", pp. 38-41, especialmente.

(9) P. GUICHARD, Nuestra Historia, vol. 3, pp. 59 y 79.

(10) A.H.N., OO.MM., Montesa, Libro 542c, fol. $134 \mathrm{r}^{\circ}-136 \mathrm{r}^{\circ}$.

(11) A.R.V., Real Patrimonio, N. ${ }^{\circ} 614$, fol. 16; A.H.N., OO.MM., Montesa, Libro 542c, fol. 136 ro-137r; A.H.M., id., libro 543c.

(12) A.H.N., OO. MM. Montesa, Libro 542c, fol. $138 v^{\circ}-139 r^{\circ}$. El documento está datado en Xativa el 8 de agosto de 1273.

(13) A.H.N., OO.MM., Montesa, Libro $542 \mathrm{c}$, fol. $137 \mathrm{r}^{\circ}-138 \mathrm{v}^{\circ}$.

(14) A.H.N., id., fol. $139 r^{\circ}-140 r^{\circ}$.

(15) A.H.N., id., Libro 871c; año 1320. 
(16) Precisamente será ya la Orden de Montesa la que como señora del lugar en 1320 arriende el molino de Portella a un vecino de Perputxent por 6 años, A.R.V., Clero, Montesa, legajo 895, caja 2357; y la que regule el uso del horno por los musulmanes en 1334.

(17) Véase P. GUICHARD, Nuestra Historia, vol. 3, pp. 33-42.

(18) A.H.N., OO.MM., Montesa, Libro 542c, fol. $140 \mathrm{v}^{\circ}-143 r^{\circ}$.

(19) Rationes Decimarum Hispanie (1279-1280), vol. I, Cataluña, Mallorca y Valencia, ed. José Rius Serra, Barcelona, 1946.

(20) A.H.N., OO.MM., Montesa, Pergaminos particulares, N. ${ }^{\circ} 408,432,438,448,449,451$; $P$. GUICHARD, Nuestra Historia, vol. 3, p. 59; A. BAZZANA, P. GUICHARD, J. M. SEGURA, op. cit., pp. $458-459$.

(21) P. GUICHARD, Nuestra Historia, vol. 3, p. 59.

(22) A.H.N., OO.MM., Montesa, Perg. particular N. 436; P. GUICHARD, Nuestra Historia, vol. 3, pp. 79-80. No estamos de acuerdo con él en que esta puebla se deba a la compra del castillo por un nuevo señor, pues hace nada menos que 9 años que se produjo dicho cambio de titularidad en el señorio, e igualmente no coincidimos en su propuesta de que dos tercios del diezmo fuesen para el señor y un tercio para la Iglesia, pues por documentos posteriores, de la época de fundación de la Orden de Montesa, Vall Perputxent es probablemente el único señorio de ella en que no tiene ninguna porción del diezmo ni de la primicia (A.H.N., OO.MM., Montesa, Libro 871c).

(23) A.R.V., Real Cancilleria, N. ${ }^{\circ} 614$, fol. 16; A.H.N., OO. MM., Montesa, Libro 542c, fol. $143 v^{\circ}-144 r^{\circ}$, e id., Libro 543c. Desde luego, el precio de venta es muy inferior al que costó el señorio en su momento, a él o a su padre, un total de 77.000 sueldos, lo que se podría interpretar como una cantidad que necesitase en ese momento a nivel personal o algo similar, más que una venta comercial estrictamente.

(24) A.H.N., OO.MM., Montesa, Libro 542c, fol. $19 \mathrm{v}^{\circ}-20 \mathrm{v}^{\circ}$.

(25) Hay 24 musulmanes - se entiende cabezas de familia-en la alqueria de L'Orxa, doce en la de Alquinencia, 18 en Benillup y 6 en la de Benitaric.

(26) Sobre las características del señorio de la Orden y de su renta feudal en el período medieval versa nuestra tesis de Doctorado en curso de realización.

(27) A.H.N., OO.MM., Montesa, Perg. particular de 11 de marzo de 1320.

(28) A.R.V., Clero, Montesa, Legajo 895, caja 2357. Le fueron pagados 753 sueldos de salario. Por cierto, que este personaje a su vez liquidaba cuentas y pagaba lo que le faltaba de salario a Berenguer Amorós, ciudadano de Valencia, quien había tenido a su cargo directamente el citado castillo de Perputxent.

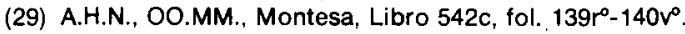

(30) A.H.N., OO.MM., Montesa, Libro 871c.

(31) El mero imperio sólo fue obtenido por Montesą el 14 de abril de 1343, cuando Pere IV se lo vendió conjuntamente con el de Sueca, Onda, Vilafamés y Montroi, únicos pueblos en los que todavia no lo tenía, A.H.N., OO.MM., Montesa, Perg. Real, N. ${ }^{\circ} 388$; A.C.A. (Archivo de la Corona de Aragón de Barcelona), Pere IV, Perg. N. ${ }^{\circ} 647$; A.R.V., Real Cancillería, N. ${ }^{\circ} 611$, fol. $126 r^{\circ}-127 r^{\circ}$.

(32) A.R.V., Clero, Montesa, Legajo 895, caja 2357.

(33) Ibídem. Gracias a estas ventas y establecimientos podemos comprobar la realidad de los censos y partición que existen sobre las tierras y, sobre todo, que dichos censos, con los cambios de propiedad, van a ir quedando fijados al tipo de tierras y no a la condición religiosa de los poseedores, tal como se ve en un establecimiento en Beniarrés hecho el 19 de agosto de 1320.

(34) A.R.V., ibidem. Es arrendado a un tal Ivanyes de Todos, con obligación de moler gratis a los que estén de custodia en el castillo, y pudiendo utilizar el trabajo de musulmanes con el salario especial a que debian trabajar para la Orden.

(35) A.R.V., ibidem. El precio del arrendamiento es de 5.200 sueldos, incluyendo todos los derechos señoriales, luismos y fadigas, excepto el monedaje y la mitad de las multas; además debe pagar él el salario al justicia y al alamín.

(36) A.R.V., Clero, Montesa, Legajo 867, caja 2279/80. Su nombramiento se produjo el 31 de marzo de 1320.

(37) A.R.V., Clero, Montesa, Legajo 867, caja 2279/80. Publicado por J. VILLARROYA, Real Maestrazgo de Montesa, València, 1787, t. II, pp. 99-101, y también por Bartomeu RIBELLES, Examen histórico-crítico del señorío... de Sueca, València, 1814. (Ed. facsímil, Sueca, 1983, t. 2, pp. 176-178.)

(38) A.H.N., OO.MM., Montesa, Libro 542c, fol. $18 r^{\circ}-19 \vee^{\circ}$. 


\section{DOCUMENTOS}

1275, abril, 25 València

Ramon de Riusec, señor de la Vall de Perputxent, da carta puebla a la alquęria de Beniarrés, para diez cristianos.

A.H.N., OO.MM., Montesa, Libro 542c, fol. $139 \mathrm{r}^{\circ} 140 \mathrm{r}^{\circ}$.

In Christi nomine et eius gratia et ad honorem beatissime Virginis Marie, matris sue, sit omnibus notum quod ego Raymundus de Rivo sicco, civis Valencia, per me et omnes meos, trado et stabilio ad bene laborandum, excolendum, plantandum et meliorandum decem populatoribus scilicet vobis, Berengario Dezroger et Petro Dezroger, filio vestro et Geraldo de Rexach et filio vestro Arnaldo Geraldi, pro uno et vobis, Raymundo de Rayg et Guillermo Geraldi et Boneto de Balasch et Petro Morlani et Ramon Deznoguer et Dominico de Gironda et Arnaldo de Benuçes et vestris perpetuo ad tascham deciman et primiciam totam alqueriam meam de Benefarez cum omnibus terminis suis et pertinensiis que est apropiata termino de perpunxen quam habeo titulo empcionis quam irde feci a donna Teresia Egidii de Bidaure et filiis suis. Ita quod totam vestram residenciam ibi faciatis perpetuo et dividatis eam inter vos ad vestram voluntatem et concedo vobis et vestris perpetuo domos unicuique vestrum ex illis videlicet que nunc ibidem sunt facte et omnes illas etiam que ibi facere volueritis iuxta voluntates vestras. Item dono er concedo vobis et vestris perpetuo scilicet unicuique vestrum singulas fanecatas terre in regadivo eiusdem pro orto, quas domos et quas fanecatas ortorum habeatis vos et vestri semper franchas absque omni censu et tributo, set e tota alia terra eiusdem detis in dot michi et meis legaliter perpetuo tascham scilicet omnium fructuum et expletorum tam terre quam arborum que dari tenetur et pro ut consuetum est dari in regno Valencie, scilicet de toto blado in area triticato et nitido et de vindemia collecta in vineis et de olivis collectis et de ficubus siccis et sa donatis et de 
amendulis collectis et ex aliis fructibus et expletis que dari debeantur et consuetum sit dari in regno Valencia. Item detis inde ecclesie deciman et primiciam suam omnium fructtum et explectorum terre et arborum eisaim et ex toto bestiarum et nutrimento similiter pro ut statutum est in regno Valencie ex hiis omnibus tantum videlicet que dari tenetur decima et primicia et non de aliis. Et retineo ibi michi et meis perpetuo turrim eiusdem alquarie cum domibus in circuitu eiusdem turris et alfondech et unam jovatam terre pro vinea in secano eiusdem et teneamini me et castrum meum de Perpunxen predictum et bona mea eiusdem custodire et defendere pro posse vestro ad bonum sanum intellectum. Et nunquam teneamini michi nec meis dare peytam aliquam neque questiam excepto host e cavalcatam que michi et meis facere teneamini, si dominus rex host vel cavalcatam petierint in Valencie et me personaliter oportuerit ire in eadem. Et sic, vos et vestri dictam alqueriam totam ab integro cum omnibus terminis suis, introitibus, exitibus, domibus, ortis, terris heremis et populatis, arboribus, cequiis, aquis, erbis, pascuis, lignis, lapidibus et venacionibus et suis universis et singulis infra se et extra se competentibus et competituris quoquomodo semper hebeatis et ipsam vobis et vestris perpetuo dono, trado et stabilio ut per dicitur ad habendum, tenendum, possidendum, explectandum et etiam ad dandum, vendendum, impignorandum, alienandum et ad omnes vestras vestrorumque voluntates libere perpetuo faciendas, exceptis militibus atque sanctis, salvo tamen semper michi et meis toto dominio meo et trascha mea, fatiga, iure, et laudimio in omnibus et per omnia ad forum Valencie, et salvis etiam michi et meis omnibus retencionibus meis ut predicitur et ecclesie decima et primicia sua, exceptis domibus predictis et ortis vobis concessis, de quibus nichil dare teneamini unquam, set non possitis ea vendere vel aliter dare nec alienare sine altera hereditate quam ibi habeatis, tamen ex ipsis domibus et ortis nunquam dare teneamini fatichas nec laudimia vel aliqua alia servicia. Quodquidem stabilimentum cum omni suo melioramento facto et faciendo promitto semper vobis et vestris salvare et defendere sub predictis condicionibus, contra omnes personas ad forum $\mathrm{Va}-$ lencie sub obligacione bonorum omnium ubique. Ad hec autem nos Berengarius Deznoguer et Petrus Deznoguer et Gueraldus de Rexach et filius eius, Arnaldus Gueraldi et Raymundus de Raig et Guillermus Geraldi et Bonetus de Balasch et Petrus Morlani et Romeus Deznoguer et Dominicus de Gironda et Arnaldus de Benuçes, per nos et omnes nostros, recepimus a vobis, predicto stabilitore, dictum stabilimentum in forma predicta et sub condicionibus antedictis sub obligacione eiusdem stabilimenti et omnium aliorum bonorum nostrorum ubique. Et ut presens instrumentum majorem obtineat firmitatem sagillo mei, predicti Raymundi de Rivosicco, feel roborari cereo pendenti. Quod est actum Valencie, in domibus eiusdem Raymundi de Rivosicco, septimo kalendas madii, anno Domini millesimo ducentesimo septuagesimo quinto.

Sig + num Raymundi de Rivossico. Sig + num Berengarii Deznoguer. Sig + num Petri Deznoguer, filii eius. Sig + num Geraldi de Rexach. Sig + 
num Arnaldi Geraldi, filii eius. Sig + num Raymundi de Raig. Sig + num Guillermi Geraldi. Sig + num Boneti de Balasch. Sig + num Petri Morlani. Sig + num Romei Deznoguer. Sig + num Dominici de Gironda. Sig + num Arnaldi de Benuçes, predictorum nos omnes qui predicta laudamus, concedimus et firmamus. Testes huius rei sunt Guillermus de Rocha, Martinus de Fontes, Bernardus Dezpoal, Martinus de Cedrelles, Guillermus de Plano et Vitalis de Sancta Maria et Perenotus Pauli. Sig + num Petri Pauli, notarii publici Valencie, qui hec scribi fecit cum suppraposito in I $\dot{X}^{a}$ linea ubi dicitur semper habeatis et ipsam.

1316, junio, 13. Perputxent Fr. Marti Perez d'Oros, castellán de Amposta de la Orden del Hospital, otorga carta puebla a los musulmanes de las alquerias de la Vall de Perputxent.

A.H.N.,OO.MM., Montesa, Libro 542c, fol. $19 v^{\circ}-20 v^{\circ}$.

Noverint universi quod nos frater Martinus Petri d'Oros ordinis Hospitalis Sancti Johannis Jherosolimitani castellanus Emposte, ex certa scientia de voluntate consensu et firmamento religiosorum fratris Arnaldi de Avinione, fratis Nicholay de Canyel, fratris Johannis d'Anyo, fratris Jacobi de Conella et aliorum fratrum et procerum nobiscum asistencium, damus, tradimus et stabilimus vobis, Saat Abenzeyt, Abrahim Almazbatch, Azmet Abenfuleyn, Çaat Almuzlim, Mahomat Abensuleyn, Hamet Aufarii, Abdala Abercarpio, Mahomat Almatbach, Abrahim Albigi, Yayhe Abafari, Maymo Abafamet, Maymon Almedioni, Abdolazis Almonge, Fazen Almoti, Abrahim Abehulem, Çaat Abehulim, Fazem Algeziri, Foto Abenfoto, Alí Benfoto, Mahomat Hubequer, Ali Behari, sarracenis, Mahomat Abengalip, Çaat Adniazquo, Çaat Albigi, sarracenis habitatoribus in valle nostra de Perpunxen, in alqueria vocata L'Orxa, et vobis Abrahim Habenyouley, Hamet Almorida, Çaet Foco, Juceff Abenagog, Hiabit Abenhalill, Mohamat Aberchando, Alim Abenharam, Mahomat Mazquo, Hamet Abenezal, Mahomat Aboniqua, Ubaquer Amfoto, Azmet Alquicip, sarracenos habitatoribus in dicta valle nostra de Perpunxen, in alqueria vocata Alquinencia, et vobis Mahomat Abeyoniz, Hiabie Abenxuquey, Hamet Habeoniz, Hamet Abellucet, Maymo Abeyoniz, Yabex Abenomar, Ali Abenali, Hamet Abucit, Mohomat Abenomar, Hazem Scrilli, Abdulaziz Almorti, Mahomat Abeniafer, Hamet Almocrati, Mahomat Abcaiallel, Hamet Abcall, Mahomat Albeatos, Abdalla Algrayt, Çat Arami, sarracenis habitatoribus in dicta 
valle nostra de Perpunxen, in alcharia vocata Benilupp, et vobis Mahomat Albofar et Hamet Perello, et Ali Perello, Hamet Almorabit, Çat Malacara, Ali Almorabit, sarracenis habitatoribus in valle nostra de Perpunxen, in alqueria vocata Benitaric, presentibus et recipientibus proprio scilicet cuilibet vestrum unum raffal et quasdam domos pro ut iam est vobis et cuilibet asignatum per alaminum nostrum de Perpunxen de voluntate nostra et terminatum. lam dictas tanquam domos et raffals pro ut per alaminum nostrum sunt vobis assignati, terminati et scilicet dictas domos cum solis, tectis et parietibus suprapositis et fundamentis introitibus, exitibus et affrontacionibus et melioramentis cumque aliis suis pertinenciis universis et singulis per omnia loca cum a celo usque in habissum, et dictos rafals cum cequiis, aquiis ad rigandum arboribus, introitibus, affrontacionibus et melioramentis cumque aliis suis pertinenciis universis et singulis per omnia loca, sic vobis cuilibet vestrum perpetuo damus, tradimus, satabilimus in hunc modum quod dictas domos et rafals laboretis et melioretis et aliquo non devoretis ad usum et consuetudinem boni adquisitoris et detis et Ordini nostro scilicet quilibet vestrum quolibet anno III solidos et medium pro bisanço regalium quos solvatis et Ordini nostro in mense januarii proxime venturo. Et per consequens quolibet anno perpetuo in dicto mense unum parum gallinarum et duos solidos pro çoffra vel quatur jornales, et duos almutos frumenti et duos solidos pro çoffra vel quatuor jornales, et duos almutos frumenti et duos almutos panici et silmo seminaveritis teneamini dare nobis et Ordini nostro unum manatam, et de qualibet colmena duos denarios et obulum, et de qualibet cabra quas teneatis in dicta valle unum denarium et obulum, et que nos possimus eligere et dare alcadi illum quam voluerimus, et quod detis nobis de vindimia de regadivo terciam partem et de vindimia de seccano VIII partem in quolibet propio, et da figulis de regadivo terciam partem et de seccano quintam partem, et de olivis quam de seccano tam de regadivo terciam partem. Et detis nobis de quolibet cafficio tam frumenti, panici, adacie quam ordi medium almuti per alaminatge. Et detis nobis quilibet vestrum pro intrata dicti stabilimenti decem solidos regalium, et sic, vobis et vestris perpetuo habeatis dictum stabilimentum possideatis et in pace perpetuo explectetis ad dandum, vendendum, impignorandum, alienandum, obligandum, excomutandum, et ad omnes vestros et vestrorum voluntates perpetuo faciendas, exceptis militibus atque sanctis, salvo tamen semper nobis et Ordini nostro censum et dictam partem fructtum, iure, dominio, laudimio et fatica in omnibus et per omnia ad forum Valencie, promittentes per nos et successores nostros dictum stabilimentum vel vestris perpetuo deffendere salvare et facere, habere, tenere et possidere quiete, potenter et in sana pace contra omnes personas conquerentes vel aliquid perturbantes ad forum Valencie. Et tenere inde vobis et cuilibet vestrum perpetuo de firma el legali eviccione et ab omni dampno ac etiam interesse, obligando scienter ac etiam vobis et vestria omnia bona et dicti ordinis mobilia et inmobilia ubique habita et habenda. Ad hec autem nos dicti sarraceni recipimus vobis dicto domino castellano dictum 
stabilimentum ad dictum censum, ad dictam partem fructuum intrata et sub formis et condicionibus antedictis. Promittimus hec omnia que superius dicta sunt a vobis attendendas et complendas. Et sic, vobis et vestris attendere firmiter et complere pro ut superius sunt expressa sine contradictu aliquo, in bona pace, obligando scienter ad hec vobis et vestris nos et omnia bona nostra mobilia et inmobilia ubique habita et habenda. Quod est actum in Perpunxen, idus junii, anno Domini $\mathrm{M}^{\circ} \mathrm{CCC}^{\circ} \mathrm{XV} I^{\circ}$. Sig + num etc.

1334, nobiembre, 14. Sueca Fr. Pere de Tous, Maestre de la Orden de Montesa, concede nueva carta puebla a los musulmanes de la Vall de Perputxent, completando algunos aspectos de la primera.

A.H.N.,OO.MM., Montesa, Libro 542c, fol. $18 r^{\circ}-19 v^{\circ}$.

Carta de la segona població del Vall de Perpuxen.

Noverint universi quod nos frater Petrus de Thous Dei gratia humilis Magister domus Militie de Muntesia, circa miloramentum utilitatem et argumentationem vallis nostre de Perpunxen et habitancium in eadem cura par vigili intendentes gratis et ex certa scientia, cum hoc presenti publico instrumento perpetuo valituro et numquam in aliquo revocaturo, per nos et succesores nostros, habita super infrascriptis delliberacione et tractatu ac colloco diligenti una cum venerabilibus et religiosis, fratre Bernardo de Roqua, operario Muntesie et comendatore de Perpunxen, fratre Dalmacio de Crudillis clavigerio Muntesie et comendatore de Çuecha, fratre Bernardo de Lacustaria comendatore de Exivert et thesaurario Ordini nostri, fratre Petro Çesolives comendatore domus Valencie et loci de Çilla, fratre Guillermo Gizperti priore nostro, fratre Arnaldo Pedriça subclavigerio Montesie, fratre Raymundo de Bagariis et fratre Arnaldo de Ribelles majore domus nostro, nobis asistentibus et de eorum expresso consilio et assensu, ad humilem supplicacionem pro parte aljame sarracenorum dicte vallis nobis, reverenter exibitam concedemus eidem aljame et singularibus personis eiusdem licet absentibus el Mahome Abozeyt et Çaat Abenolayt, sarracenis habitantibus in alcharea de L'Orxa, sita in valle predicti, nunciis ad nos per dictam aljaman super infrascriptis, noviter transmissis presentibus et hoc instrumentum et contenta in eo nomine dicte aljame recipientibus èt notario infrascripto tanquam publice persone hec a nobis pro ipsa aljama et singularibus eiusdem in pro aliis 
etiam personis quarum interest et interesse potest et poterit legitime stipulanti et recipienti, quod de cetero universi er singuli sarraceni, in dicta valle habitantes el habitaturis possit in perpetuum decoquere seu decoqui facere in domibus suis, videlicet ad tenore seu alio quocumque modo pro ut eis melius videbitur expedire panes suos et omnia alia que inibi fuerint decoquenda et non in furno seu furnis constructis iam vel de cetero construendis in valle predicta absque aliqua scilicet pugia et alio quolibet jure excepto temen furnatico infrascripto volentes ac perpetuo firmiter statuentes quod nunquam de cetero dicti sarraceni vel aliquis seu aliqui ipsorum compellantur seu compelli valeant ullo modo, per nos seu ordinem nostrum vel comendatorem dicti castri aut per aliquam personam nostro vel ipsius nomine ad decoquendum in dicto furno seu furnis constructus ut predicitur et de cetero construendis in dicta valle dictos panes vel alia que fuerint decoquenda nisi tamen in domibus suis ut superius continentur; salvo tamen et retento nobis et Ordini nostro, quod quelibet persona in etate trium annorum constituta et de tribus annis ultra teneatur exolvere nobis et Ordini nostro seu comendatori dicti loci in primo venturo festo Sancti Martini et deinde anno quolibet perpetuo in eodem termino sive festo pro furnativo sive iure furnorum octo denarios regalium pro qualibet cabecia et non ultra.

Item concedimus dicte aljame et singularibus eiusdem quod de cetero possint facere seu fieri facere aratra et omnia alia apparamenta laboracionis ubicumque voluerint absque aliquo scilicet metu, pene seu calonie que eis nunquam super hoc imponi valeat ullo modo et quod nunquam valeant compelli, distringi seu forciari ex parte ordinis nostri ad faciendum dicta aratra seu alia apparamenta laboracionis cum aliqua persona sed possint ea licite facere ubicumque voluerint ut superius continetur; salvo tamen et retento nobis et Ordini nostro quod pro recognitione huius modi gracie, teneatur dicta aljama dare et solvere nobis et Ordini suppradicto seu comendatori dicti castri, anno quolibet perpetuo in dicta feste Sancti Martini, decem solidos dicte monete et non amplius.

Item volumus, concedimus, statuimus ac in perpetuum ordinamus quod quotienscumque nos vel comendator dicti castri, necessarios habuerimus dictos sarracenos vel aliquem ipsorum sive animalia ipsorum sive animalia eorum, ad aliqua opera de novo facienda sive ad reparaciones vel alia quecumque, quod possimus eos et ea accipere ad nostre libitum voluntatis, cum salario tamen quod inde eis dare et solvere die quolibet teneamur videlicet pro quolibet sarraceno sive asina $\mathrm{VI}^{\circ}$ denarios, et pro asino seu asina alios $V I^{\circ}$ denarios, et pro mulo seu mulla XII denarios, pro dis qualibet quamdiu ipsos et ipsa necessarios seu necessaria habuerimus.

Item volumus concedimus, statuimus et ordinamus in perpetuum quod si nos vel comendator dicti loci necessarios habuerimus gallinas et duos pullos aut pullas, quod possimus eas et eos accipere quocumque nobis placuerit, dando et solvendo pro quolibet pari gallinarum 
duodecim denarios, et de quolibet edo sive cabrit alios duodecim denarios, et de quolibet pari pullorum sex denarios, et de quolibet pari pullarum octo denarios.

Item volumus, ordinamus et omnino prohibemus quod de cetero dicti sarraceni non teneantur dare custodi seu guardiano vinearum et aliorum honerum et possessionum suarum dicte vallis instrumentum unam barcellam inter frumentum, ordeum, adacçam et panicium pro hereditatem qualibet, et unam garbam lini et non amplius pro ut extitit attenus assuetum huius modi autem gracias concessiones facimus per nos et successores nostros de consilio et assensu fratrum predictorum, sicut melius dici et scribi et intelligi potest ad salvamentum et bonum intellectum dicte aljame et dingularium eiusdem, salvis tamen nobis et Ordini retencionibus supradictis et salvis etiam et retentis nobis et dicto Ordini çoffra, bisancio et aliis quibuslibet iuribus que sarraceni dicte vallis sunt eidum Ordini hactenus solvere consueti. Promittentes per nos et successores nostros eidem aljame et singularibus eiusdem licet absentibus et dictis Mahome Abezeyt et Çaat Abenolayt presentibus et hoc instrumentum et contenta in eo nomine ipsius aljame recipientibus et notario infrascripto, tanquam publice persone hec a nobis pro ipsa aljama et pro aliis etiam personis quarum interest et interesse potest et poterit legitime stipulanti et recipienti quod predicta omnia et singula tenebimus firmiter perpetuo et observabimus et teneri et observari inviolabiliter faciemus ut superius continetur, et non contraveniemus nec aliquem contravenire faciemus, consentiemus seu permittemus aliquo jure, foro, causa vel ratione. Mandantes nichilominus cum hoc presenti publico instrumento quo ad hec vicem epistole gerenti comendatori dicti loci, nec non universis aliis comendatoribus et fratribus ac officialibus Militie supradúe vel eorum loca tenentibus, tam presentibus quam futuris, quod huius modi concessiones, gracias, ordinaciones, statuta et prohibicionem nostras teneant firmiter et observent et ab omnibus teneri faciant perpetuo ac inviolabiliter observari ut superius expressantur et non contraveniant nec aliquem contravenire permittant aliquo iure, foro, causa vel etiam ratione. In cuius rei testimonium presens instrumentum dicte aljame inde fieri et dictis nunciis suis nomine recipientibus tradi iussimus, per notorium insfrascriptum, sigili nostri pendentis munimine roboratum. Quod est actum in villa de Cuecha, $X \mathrm{XVII}^{\circ}$ kalendas decembris anno Domini $\mathrm{M}^{\circ} \mathrm{CCC}^{\circ} \mathrm{XXX}$ quarto. Sig + num fratris Petri de Thous, De gratia Magistri domus Militie de Muntesia, sig + num fratris Bernardi de Roque, sig + num fratris Dalmacii de Crudiliis, sig + num fratris Bernardi de Lacustaria, sig + num fratris Petri Çesolives, sig + num fratris Guillermi Gizperti, sig + num fratris Arnaldi Pedriça, sig + num fratris Raymundi de Baganes, sig + num fratris Arnaldi de Ribelles, predictorum qui hec laudamus, concedimus et firmamus. 